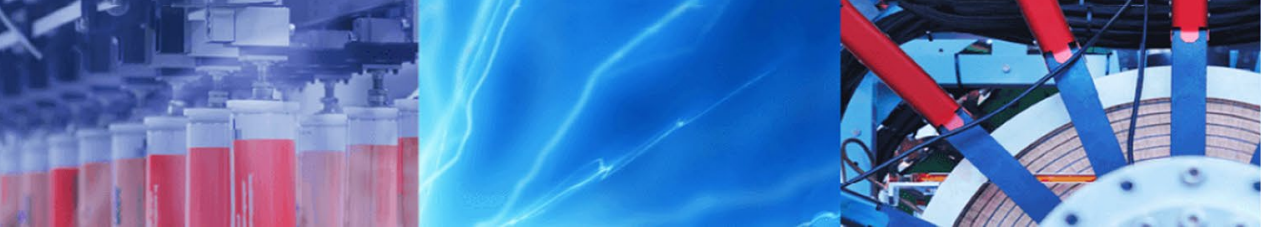

Research Article

\title{
3PA-induced optical limiting in pure and barium borate decorated $\mathrm{MoS}_{2}$ nanocomposites
}

\author{
M. Durairaj ${ }^{1}$ T. C. Sabari Girisun ${ }^{1}$ · S. Venugopal Rao²
}

Received: 27 November 2019 / Accepted: 22 April 2020 / Published online: 5 May 2020

(c) Springer Nature Switzerland AG 2020

\begin{abstract}
Pure $\mathrm{MoS}_{2}$ and barium borate nanorods embedded $\mathrm{MoS}_{2}$ microspheres were successfully synthesized by adopting an environmental-friendly hydrothermal method. Powder XRD data confirmed the formation of BBO: MoS $_{2}$ nanocomposite made of barium borate $\left[2 \theta=22^{\circ},(018)\right]$ along with the $\operatorname{MoS}_{2}\left[2 \theta=14^{\circ},(002)\right]$. The presence of few layers $\operatorname{MoS}_{2}$ was ascertained from the measured difference in characteristic $E_{2 g}^{1}\left(379 \mathrm{~cm}^{-1}\right)$ and $A_{1 g}\left(407 \mathrm{~cm}^{-1}\right)$ Raman modes of $\operatorname{MoS}_{2}$. FESEM images portrayed the formation of microspheres for pure $\mathrm{MoS}_{2}$ due to reduction in the surface energy induced by citric acid. In the nanocomposite, barium borate embedded themselves as nanorods upon $\mathrm{MoS}_{2}$ microsphere forming an urchin-like structure. Ground-state absorption studies revealed a hyperchromic shift in absorption peak due to the overlapping of transition states between highly transparent barium borate and strongly absorbing $\mathrm{MoS}_{2}$ in the visible region. Femtosecond laser pulses $(800 \mathrm{~nm}, 150 \mathrm{fs}, 80 \mathrm{MHz}$ ) were employed to perform the open-aperture Z-scan experiments revealing that both pure $\mathrm{MoS}_{2}$ and $\mathrm{BBO}: \mathrm{MoS}_{2}$ nanocomposites possessed reverse saturable absorption (RSA), attributed to both 2PA and 3PA processes. Interestingly, pure $\mathrm{MoS}_{2}$ exhibited sequential 3PA (1PA + 2PA) due to the presence of near-resonant energy states, while the dominance of transparent $\mathrm{BBO}$ in the nanocomposite induced genuine/ instantaneous 3PA process. In closed-aperture Z-scans (for determining the sign and magnitude of nonlinear refraction), the pattern switched from self-focusing $\left(\mathrm{MoS}_{2}\right)$ to self-defocusing (BBO: $\mathrm{MoS}_{2}$ ) nature. Both pure $\mathrm{MoS}_{2}$ and BBO: $\mathrm{MoS}_{2}$ nanocomposites exhibited strong optical limiting with a lower onset limiting threshold $\left(0.11 \mu \mathrm{J} / \mathrm{cm}^{2}\right)$ due to synergetic effects of nonlinear absorption (3PA) and nonlinear refraction (self-defocusing). BBO:(0.02 M) $\mathrm{MoS}_{2}$ nanocomposite possessing a urchin structure depicted strong NLO coefficients with $\gamma_{3 P A}=2.12 \times 10^{-21} \mathrm{~m}^{3} / \mathrm{W}^{2}, n_{2}=-11.1 \times 10^{-17} \mathrm{~m}^{2} / \mathrm{W}$ and $\chi^{(3)}=14.0 \times 10^{-19} \mathrm{~m}^{2} / \mathrm{V}^{2}$, which were higher than pure $\mathrm{MoS}_{2}$ and other composites.
\end{abstract}

Keywords $\mathrm{MoS}_{2}$ decorated barium borate $\cdot$ Hydrothermal $\cdot$ Two-/three-photon absorption $\cdot$ Z-scan

\section{Introduction}

A wide variety of inorganic and organic materials are being extensively investigated to achieve efficient nonlinear optics (NLO)-driven devices for applications such as in laser medicine, signal processing, defence and precision measurement. Over the past few years, graphene, twodimensional transition metal dichalcogenides (TMDC), topological insulators $(\mathrm{TI})$, metal organic frameworks (MOF) have been investigated extensively as a promising optical limiting material for laser safety devices and saturable absorber for ultrafast fibre lasers [1-3]. Among TMDCs, molybdenum disulphide $\left(\mathrm{MoS}_{2}\right)$ has garnered increasing attention, primarily because of its peculiar band structure with exotic properties and represents an abundant, geographically ubiquitous and potentially cheap analogue

$\triangle$ T. C. Sabari Girisun, sabarigirisun@bdu.ac.in; S. Venugopal Rao, soma_venu@uohyd.ac.in | ${ }^{1}$ Nanophotonics Laboratory, Department of Physics, Bharathidasan University, Tiruchirappalli 620024, India. ${ }^{2}$ Advanced Centre of Research in High Energy Materials (ACRHEM), University of Hyderabad, Hyderabad, Telangana 500046, India. 
of graphene [4]. It is a typical transition metal sulphide with a layered structure of covalently bonded S-Mo-S, which is bonded to adjacent layers by weak van der Waals ( $\mathrm{vdW}$ ) interactions between neighbouring S-S layers [5]. It possesses layer-dependent optical, electrical and thermal properties, i.e. the bandgap of $\mathrm{MoS}_{2}$ decreases with increase in the number of layers due to the quantum confinement effects (direct band gap: $1.9 \mathrm{eV}$ to indirect band gap: $1.2 \mathrm{eV}$ [6]. The ultimate crossover from direct to indirect bandgap nature can be accounted for a combined effect of quantum confinement and long-range columbic effects [7]. Further, thermal conductivity of the $\mathrm{MoS}_{2}$ decreases from bulk material to a lower dimension nanostructures [8]. Earlier works on the investigation of NLO properties of pure $\mathrm{MoS}_{2}$ revealed a saturable absorption (SA) behaviour, i.e. for higher input powers the absorption becomes nonlinear and the material exhibited high transmittance [9]. An interesting switch-over in the nonlinear absorption behaviour of $\mathrm{MoS}_{2}$ saturable absorption to reverse saturable absorption was demonstrated through nanocomposites formation [10]. Especially, incorporating $\mathrm{ZnO}$ [11], $\mathrm{TiO}_{2}$ [12] and organic polymers like PMMA [13] yielded reverse saturable absorption (RSA) due to twophoton absorption (TPA) based optical limiting in different $\mathrm{MoS}_{2}$ nanocomposites. Optical limiting experiments on $\mathrm{ZnO}$ and PMMA composites with $\mathrm{MoS}_{2}$ demonstrated low onset optical limiting threshold of $1.1 \mathrm{~J} \mathrm{~cm}^{-2}, 2.3 \mathrm{~J} \mathrm{~cm}^{-2}$, respectively [11]. Impressed by the interesting NLO behaviour of $\mathrm{MoS}_{2}$ nanocomposites, this article attempts to replace the above mentioned decorative materials with a well-known inorganic NLO material, beta barium borate (BBO). The chosen decorative exhibits many interesting properties such as wide transparency (190-3500 nm), high laser damage threshold, large birefringence and good mechanical properties suitable for NLO devices [14]. Therefore, by incorporating BBO, the major concern of lower linear transmittance in the visible-NIR region can be circumvented in $\mathrm{MoS}_{2}$, which in turn makes them suitable for optical limiting applications. Often, these nanocomposites are expected to possess strong thermal stabilities which are essential for performing optical limiting action using intense ultrashort pulses. Additionally, advanced photonic materials made up of materials having extreme nonlinear absorption (reverse saturable and saturable absorption) are attractive for laser photonic devices such as optical limiters and mode lockers [15]. Thus, the combination of saturable absorbing $\mathrm{MoS}_{2}$ with reverse saturable absorbing BBO nanostructures can be a potential system to investigate nonlinear absorption-based optical limiting for widely developing femtosecond IR lasers. These materials can be utilized to protect optical sensors from damage against the intense laser pulses and interrupt the transmission of a powerful laser pulse to eye-safe levels. Thus, the
NLO properties of pure $\mathrm{MoS}_{2}$ and BBO decorated on different molar concentration of $\mathrm{MoS}_{2}$ were studied by openaperture (OA) and closed-aperture (CA) Z-Scan technique using femtosecond laser pulses ( $800 \mathrm{~nm}, 150 \mathrm{fs}, 80 \mathrm{MHz}$ ). Such an investigation helps us to further the understanding of NLO responses at nanoscale and provide avenues to develop new promising optical limiters for highly dangerous ultrafast IR laser pulses.

\section{Material preparation}

Preparation of pure $\mathrm{MoS}_{2}$ and decoration of $\mathrm{BBO}$ on the surface of $\mathrm{MoS}_{2}$ structure were achieved by simple onepot hydrothermal technique. Initially, sodium molybdate and thiourea were taken in ratio of 2:3 and were dissolved in $120 \mathrm{ml}$ distilled water. To control the agglomeration in the $\mathrm{MoS}_{2}$ system, citric acid was added as a surfactant. The homogeneous white solution obtained on addition of citric acid was transferred to $150 \mathrm{ml}$ Teflon-lined autoclave set-up and maintained at $180^{\circ} \mathrm{C}$ for $24 \mathrm{~h}$ [16]. Following heat treatment, the solution was brought to room temperature naturally. The acquired black colour suspension in an orange colour solution was washed several times using ethanol and water and filtered repeatedly to remove the excess surfactant from the suspension. Finally, the obtained powders were kept at $200^{\circ} \mathrm{C}$ in an oven to remove the adsorbed water molecules. For decoration of $\mathrm{BBO}$ on $\mathrm{MoS}_{2}$, barium chloride, boric acid and sodium hydroxide were dissolved in $80 \mathrm{ml}$ distilled water and kept at stirring for one hour [17]. After $30 \mathrm{~min}, 0.01 \mathrm{M}, 0.02 \mathrm{M}$ and $0.03 \mathrm{M}$ concentration of acquired $\mathrm{MoS}_{2}$ powders were added to the solution and kept at $120^{\circ} \mathrm{C}$ for $24 \mathrm{~h}$. The acquired BBO: $\mathrm{MoS}_{2}$ particles were repeatedly washed and dried at $400^{\circ} \mathrm{C}$ for $3 \mathrm{~h}$ resulting in the formation of ash white colour powder.

\section{Preliminary identification: XRD}

Preliminary confirmation of the material formation was achieved through powder XRD studies employed with Rigaku Ultima IV XRD at the scan speed of 7.19 degrees/ min. The recorded XRD pattern of prepared pure and barium borate decorated $\mathrm{MoS}_{2}$ is as shown in Fig. 1. The formation of pure $\mathrm{MoS}_{2}$ and BBO: $\mathrm{MoS}_{2}$ nanocomposites was confirmed through indexing the observed XRD diffraction peaks using JCPDS card Nos. 065-1951 ( $\left.\mathrm{MoS}_{2}\right)$ and 015-0862 (BBO). Identified diffraction crystal planes of $\mathrm{MoS}_{2}$ are (002), (004), (100), (102), (103), (105), (106), (110), (112) which corresponds to the angle $2 \theta=14^{\circ}, 29$ ${ }^{\circ}, 32^{\circ}, 34^{\circ}, 39^{\circ}, 47^{\circ}, 55^{\circ}, 58^{\circ}, 60^{\circ}$ and beta barium borate are (018), (110), (1010), (202), (205), (119), (1112), (218), (306),

\section{SN Applied Sciences}




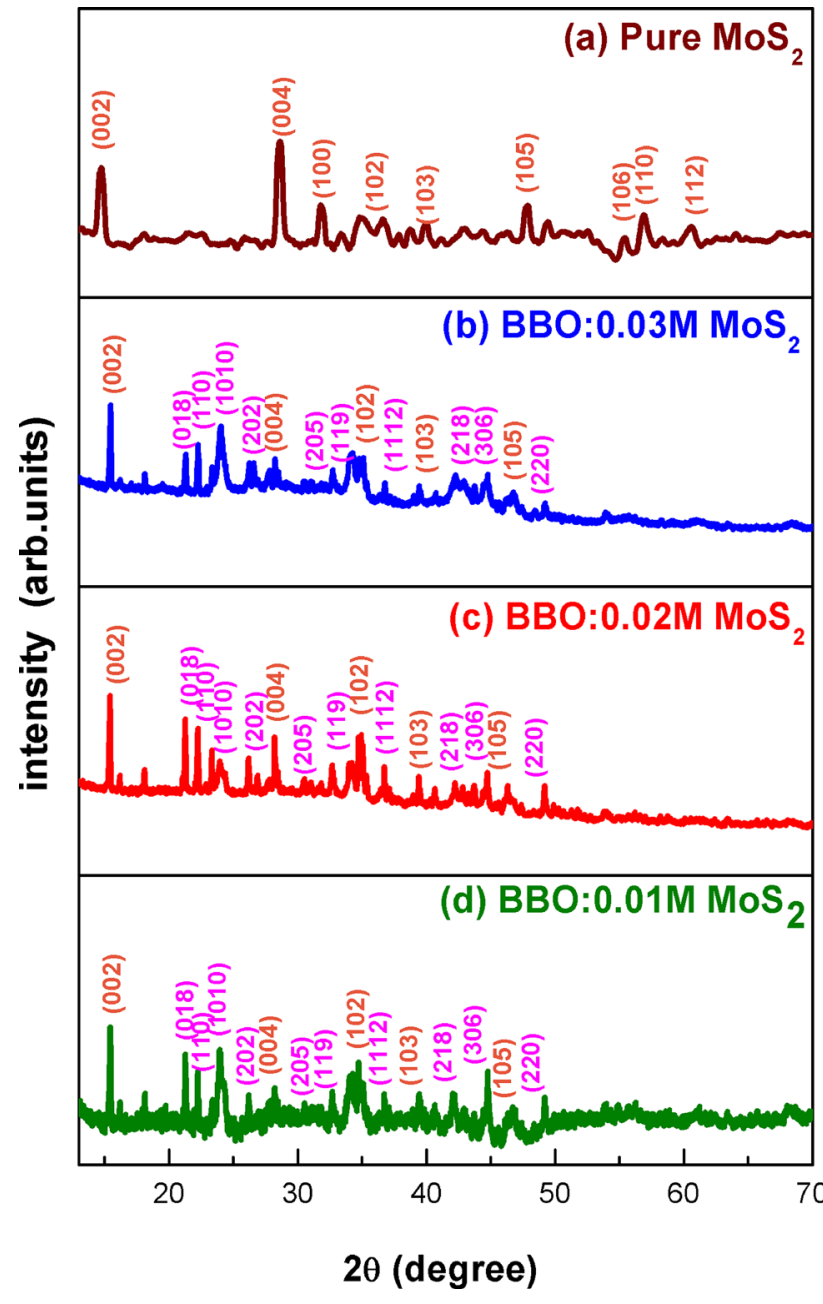

Fig. 1 XRD patterns of (a) pure $\mathrm{MoS}_{2}$ and barium borate decorated (b) $0.03 \mathrm{M} \mathrm{MoS}_{2}$ (c) $0.02 \mathrm{M} \mathrm{MoS}_{2}$ (d) $0.01 \mathrm{M} \mathrm{MoS}_{2}$ composites

(220) that corresponds to the angle $2 \theta=22^{\circ}, 24^{\circ}, 26^{\circ}, 28^{\circ}$ $, 32^{\circ}, 34^{\circ}, 37^{\circ}, 42^{\circ}, 45^{\circ}, 50^{\circ}$, respectively. Literature reports show that $\mathrm{MoS}_{2}$ has a hexagonal shape unit cell with $\mathrm{P \sigma}_{3}$ / mmc space group, i.e. each layer of $\mathrm{MoS}_{2}$ is composed of $\mathrm{S}-\mathrm{Mo}-\mathrm{S}$ stacks, where a single molybdenum atom is surrounded by six sulphur atoms. Similarly, beta barium borate crystallizes in the R3c space group with rhombohedral structure having lattice constant of $a=b=7.3 \AA$ and $\mathrm{C}=39 \AA \AA$. In pure $\mathrm{MoS}_{2}$, diffraction peaks of (002) and (004) are highly intense compared to the other peaks, which expose the presence of well stacked layered structure of $\mathrm{MoS}_{2}$ [18]. As the concentration of $\mathrm{MoS}_{2}$ varied as $0.01 \mathrm{M}, 0.02 \mathrm{M}$ and $0.03 \mathrm{M}$ in the BBO: $\mathrm{MoS}_{2}$ composite, major diffraction peak of $\mathrm{MoS}_{2}$ (002) suffered a small shift in $2 \theta\left(=15^{\circ}\right)$ position due to the surfactant. However, the diffraction peaks of barium borate remain unchanged in different concentrations of $\mathrm{MoS}_{2}$ which shows the dominance of crystalline nature of $\mathrm{BBO}$ in composite. Absence of any other peaks that corresponds to the by-products, impurities or other phases of title compound signifies the formation of pure and BBO decorated $\mathrm{MoS}_{2}$. Thus, preliminary confirmation made using XRD ascertain the formation of BBO: $\mathrm{MoS}_{2}$ composite without destructing its original crystal structure.

\section{Molecular vibrations analysis: Raman spectroscopy}

Molecular structural arrangement of $\mathrm{MoS}_{2}$ and barium borate decorated on different concentration of $\mathrm{MoS}_{2}$ was studied by Raman spectroscopy in the spectral range of $100-1500 \mathrm{~cm}^{-1}$. Two characteristic peaks were observed at low range for pure $M_{2} S_{2}$ at $379 \mathrm{~cm}^{-1}$ and $407 \mathrm{~cm}^{-1}$ which corresponds to in-plane $E_{2 g}^{1}$ and out-of-plane $A_{1 g}$ vibrational modes of the $\mathrm{MoS}_{2}$. At in-plane vibration mode, sulphur $S$ atoms vibrate in one direction and molybdenum $M o$ atom vibrates in another direction and at out-of-plane vibration mode, sulphur $S$ atoms only vibrate in a vertical direction. It is known that with increase in number of single layers the $A_{1 g}$ mode shifts to higher frequencies and the $E_{2 g}^{1}$ mode shifts to lower frequencies, i.e. difference between the corresponding peak frequency of $A_{1 g}$ and $E_{2 g}^{1}$ increases as a function of numbers of layer. Earlier report on Raman spectrum of $\mathrm{MoS}_{2}$ exposes that single layer of $\mathrm{MoS}_{2}$ shows $A_{1 g}$ and $E_{2 g}^{1}$ peaks at $405 \mathrm{~cm}^{-1}$ and $384 \mathrm{~cm}^{-1}$ [19]. Here in the present case, Raman spectrum of pure $\mathrm{MoS}_{2}$ prepared by hydrothermal method shows $A_{1 g}$ and $E_{2 g}^{1}$ peaks at $407 \mathrm{~cm}^{-1}$ and $379 \mathrm{~cm}^{-1}$, respectively. Difference in the peak position (Fig. 2) of pure $\mathrm{MoS}_{2}$ with earlier report [19] and shift in $A_{1 g}$ peak towards higher wavenumber and $E_{2 g}^{1}$ peak towards lower wavenumber can be attributed to the change in layer number obtained in surfactant assisted hydrothermal method. Also in the Raman spectrum of composites, $A_{1 g}$ mode encountered a shift towards higher wavenumber $419 \mathrm{~cm}^{-1}$ and it represents the increase in layer thickness during composite formation, while $E_{2 g}^{1}$ mode exhibited relatively weak vibration due to the thermal exfoliation at $400{ }^{\circ} \mathrm{C}$ and it corresponds to the increase in crystal defect states [20]. Further the dominance of $\mathrm{BBO}$, suppressed the $E_{2 g}^{1}$ and $E_{g}^{1}$ vibrational peaks of $\mathrm{MoS}_{2}$. Although minimal variations in intensity of BBO were observed in nanocomposites, Raman spectrum was not altered significantly due to dominance of $\mathrm{BBO}$ vibrations and lower concentration of $\mathrm{MoS}_{2}$. The notable characteristic peaks of $\mathrm{BBO}$ in nanocomposites are 493 and $602 \mathrm{~cm}^{-1}$ (intra-ring bending vibration of $\left.\mathrm{BO}_{3}\right), 703 \mathrm{~cm}^{-1}$ (symmetric breathing vibration of $\mathrm{B}-\mathrm{O}$ ), $812 \mathrm{~cm}^{-1}$ (symmetric B-O-B bridge bond vibration), 913 , 996,1115 (asymmetric stretching of $\mathrm{BO}_{4}$ ) and $1264 \mathrm{~cm}^{-1}$ 

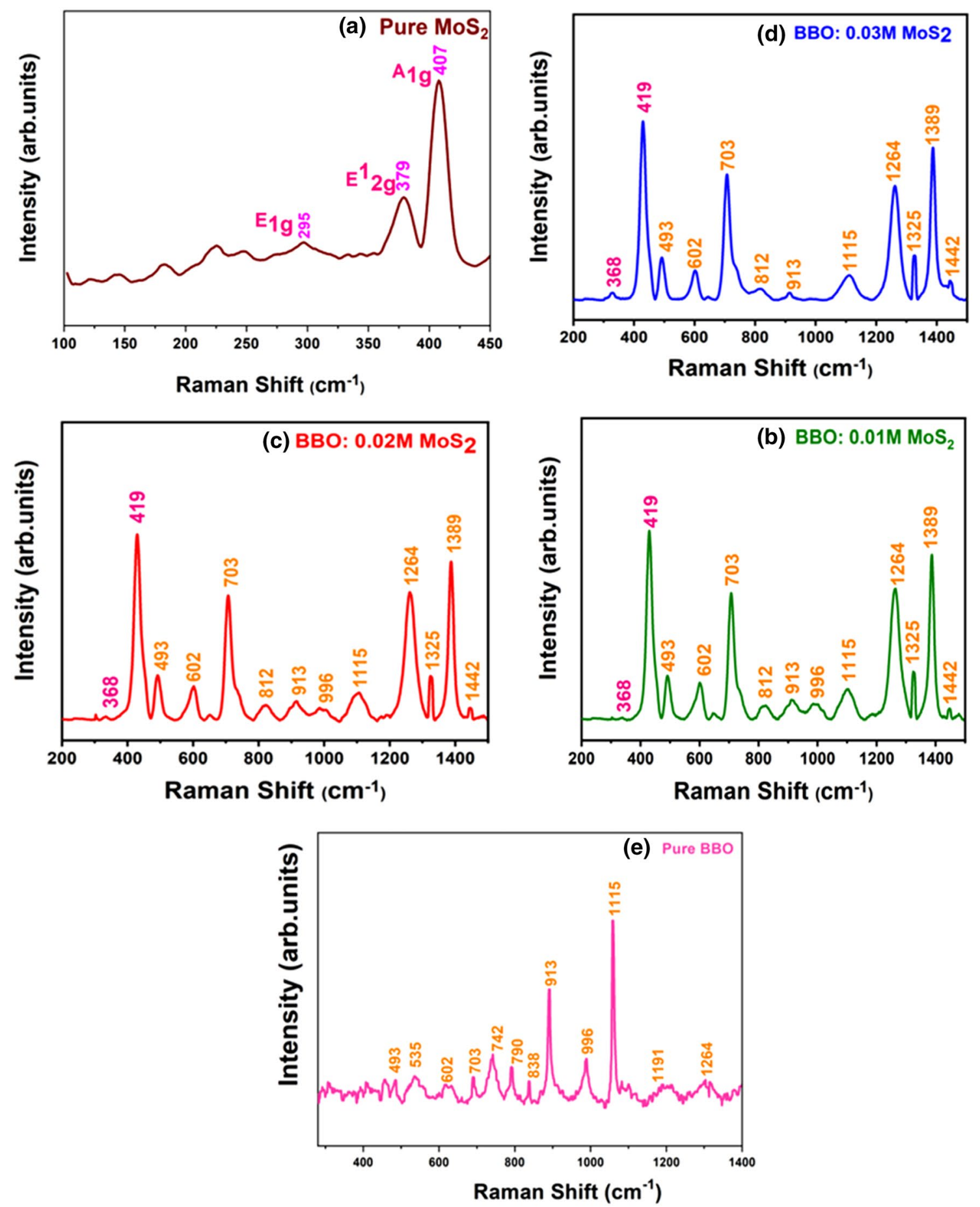

Fig. 2 Raman spectra of (a) pure $\mathrm{MoS}_{2}$ and barium borate decorated (b) $0.03 \mathrm{M} \mathrm{MoS}_{2}$ (c) $0.02 \mathrm{M} \mathrm{MoS}_{2}(\mathbf{d}) 0.01 \mathrm{M} \mathrm{MoS}_{2}$ composites (e) pure BBO [17]

(symmetric vibration of $\mathrm{B}_{2}-\mathrm{O}_{3}$ group), 1325, 1389 and $1442 \mathrm{~cm}^{-1}$ (stretching vibration of the terminal $\mathrm{B}-\mathrm{O}_{3}$ ). It is clearly inferred that almost all the $\mathrm{BBO}$ vibrations are observed in the Raman spectra of nanocomposite along with the characteristic vibrations of $\mathrm{MoS}_{2}$, thereby confirming the formation of BBO: $\mathrm{MoS}_{2}$ composite without any molecular defects. 
Fig. 3 Morphological images of (a) Pure $\mathrm{MoS}_{2}$ and barium borate decorated (b) $0.03 \mathrm{M}$ $\mathrm{MoS}_{2}$ (c) $0.02 \mathrm{M} \mathrm{MoS}_{2}$ (d) $0.01 \mathrm{M} \mathrm{MoS}_{2}$ and (e) schematic of the pictorial growth mechanism of pure $\mathrm{MoS}_{2}$ and barium borate on $\mathrm{MoS}_{2}$
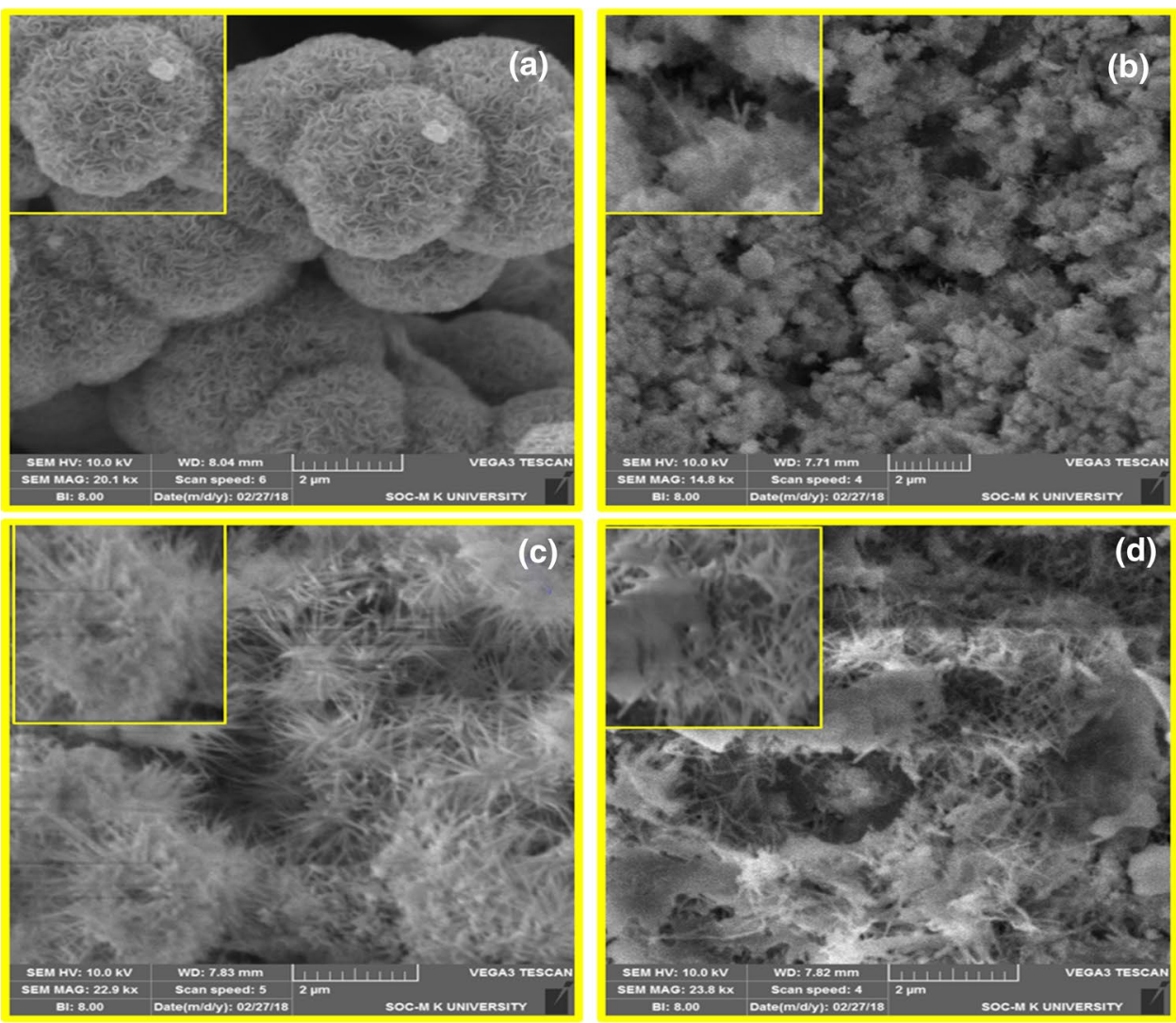

(e)
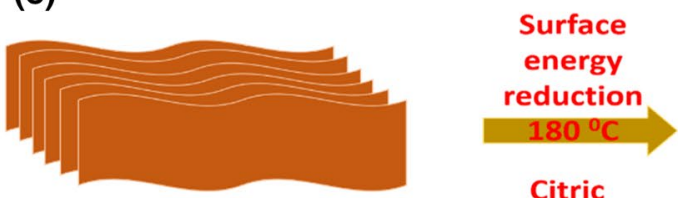

Citric

$\operatorname{MoS}_{2}$ layers

acid

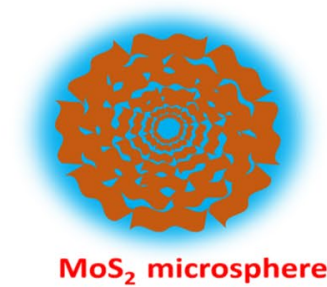

(cross section)

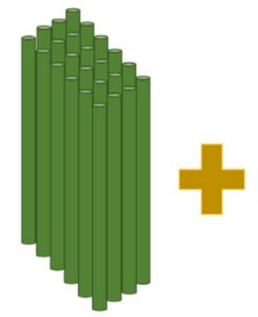

BBO Nanorod
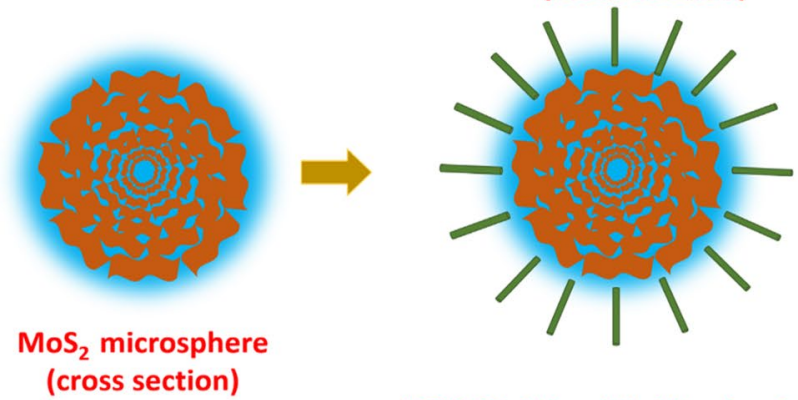

(BBO: $\mathrm{MoS}_{2}$ ) urchin like structure

\section{Morphological analysis: SEM}

The morphological images (Fig. 3) of pure and barium borate decorated $\mathrm{MoS}_{2}$ were recorded using a scanning electron microscope (VEGA3 TESCAN). It can be clearly visualized that $\mathrm{MoS}_{2}$ appears like a microsphere (Fig. 3a), while BBO decorating on $\mathrm{MoS}_{2}$ microsphere appears like an urchin structure (Fig. $3 \mathrm{~b}-\mathrm{d}$ ). In general, $\mathrm{MoS}_{2}$ is a $2 \mathrm{D}$ layered structure material in which molybdenum $\left(\mathrm{Mo}^{+}\right)$ and sulphur $\left(S^{-}\right)$atoms are assembled in a same plane to form themselves like nanosheets. In the present case, the possible formation of $\mathrm{MoS}_{2}$ microsphere is due to the reduction of surface energy induced by the citric acid surfactant. Here, the surfactant (citric acid) act as a reducing agent, which easily reduces $\mathrm{Mo}^{6+}$ to $\mathrm{Mo}^{4+}$, and then bond with $S^{2-}$ [16]. Formed $\mathrm{MoS}_{2}$ nanosheets roll themselves 
together and aggregate into marigold flower like structure with average diameter of $2.68 \mu \mathrm{m}$ through an electrostatic interaction between the nucleates of $\mathrm{MoS}_{2}$ and citric acid. In the BBO: $\mathrm{MoS}_{2}$ nanocomposites, with increase in $\mathrm{MoS}_{2}$ concentration, transformation of microsphere (pure and $0.03 \mathrm{M} \mathrm{MoS}_{2}$ ) to urchin (0.02 $\mathrm{M} \mathrm{MoS}_{2}$ ) to layer (0.01 $\mathrm{M} \mathrm{MoS}_{2}$ ) like morphology was witnessed. Earlier report shows that $\mathrm{BBO}$ grows as elongated nanorod due to the prolonged heating at $120^{\circ} \mathrm{C}$ for $24 \mathrm{~h}$ [17]. In the BBO: $\mathrm{MoS}_{2}$ composite, $\mathrm{BBO}$ grow themselves as nanorod with an average length of $0.92 \mu \mathrm{m}\left(0.03 \mathrm{M} \mathrm{MoS}_{2}\right), 1.21 \mu \mathrm{m}$ $\left(0.02 \mathrm{M} \mathrm{MoS}_{2}\right), 1.32 \mu \mathrm{m}\left(0.01 \mathrm{M} \mathrm{MoS}_{2}\right)$ upon the $\mathrm{MoS}_{2}$ microspheres. The possible mechanism is that barium nucleate themselves upon the surface of readily available $\mathrm{MoS}_{2}$ microspheres and form themselves as BBO nucleates which then grow into $\mathrm{BBO}$ nanorods under prolonged heating (Fig. 3e). At higher concentration (0.03 M) of $\mathrm{MoS}_{2}$, slightly agglomerated $\mathrm{MoS}_{2}$ microsphere (due to thermal shocking applied at $400^{\circ} \mathrm{C}$ for composite formation) with traces of smaller length BBO rods was observed confirming the transition of microsphere to urchin-like structure. Interestingly at $0.02 \mathrm{M} \mathrm{MoS}_{2}$, these $\mathrm{BBO}$ nanorods strongly embed on the surface of the $\mathrm{MoS}_{2}$ microsphere to appear like an urchin structure $\left(0.02 \mathrm{M} \mathrm{MoS}_{2}\right)$ with a diameter $1.69 \mu \mathrm{m}\left(\mathrm{MoS}_{2}\right.$ microsphere) and length $1.2 \mu \mathrm{m}$ (barium borate nanorod) (Fig. 3c). At lower concentration (0.01 M) of $\mathrm{MoS}_{2}$, due to higher density of BBO nanorods the microspheres structure got destructed to form a sheet-like structure. This mainly arises because interlayer distance of $\mathrm{MoS}_{2}$ in microsphere morphology was increased due to the incorporation of barium borate. Thus, the formation of peculiar urchin structure BBO: $\mathrm{MoS}_{2}$ nanocomposite can be advantageous for laser applications due to the availability of spherical $\mathrm{MoS}_{2}$ (higher stability) along with 1D $\mathrm{BBO}$ rods (confined optical excitations).

\section{Linear optical studies: absorption spectroscopy}

The recorded linear optical absorption spectrum (Fig. 4) of pure and BBO decorated $\mathrm{MoS}_{2}$ was studied by UV-Visible spectrophotometer (ELICO-SL159) in the range of 190-800 $\mathrm{nm}$. The absorption maximum of $\mathrm{MoS}_{2}$ was observed at $271 \mathrm{~nm}$ with absorption edge at $350 \mathrm{~nm}$, which can be attributed to the excitonic features of $\mathrm{MoS}_{2}$ microspheres. It has a strong absorption at visible to near infrared $(400-800 \mathrm{~nm})$ region due to the direct transition of excitons at $\mathrm{K}$ point of Brillouin zone. In BBO: $\mathrm{MoS}_{2} \mathrm{com}-$ posite, the absorption maximum of $\mathrm{MoS}_{2}$ was blue shifted to $266 \mathrm{~nm}$ from $271 \mathrm{~nm}$ when decorating the barium borate nanoparticles upon $\operatorname{MoS}_{2}$. Literature reports reveal that absorption maxima of beta barium borate nanorods were found at $201 \mathrm{~nm}$ and exhibit complete transparency throughout the visible region [14]. Here, the absorption peak of barium borate was observed at $222 \mathrm{~nm}$ which was strongly red shifted compared to its bulk form due to the influence of 1D morphology and $\mathrm{MoS}_{2}$ interaction. Also, in the composite the intensity of absorbance increases with increase in the concentration of $\mathrm{MoS}_{2}$. The absorbance of BBO: $\mathrm{MoS}_{2}$ composite is found to be low throughout the visible spectral region when compared with pure $\mathrm{MoS}_{2}$. This hypochromic shift in the absorbance of BBO: $\mathrm{MoS}_{2}$ clearly shows that the high linear transmittance (transparent properties) of composite arises from the contribution of highly transparent barium borate. Hyperchromic shift in absorption peak was due to the overlapping of transition states between highly transparent BBO and strongly absorbing $\mathrm{MoS}_{2}$ in visible region. Similar observation was made for the BBO: $\mathrm{rGO}$ nanocomposites in which the maximum absorption peak of BBO $(207 \mathrm{~nm})$ was red shifted due to the restored electronic conjugation within the sheets of $\mathrm{rGO}$ and inclusion of barium borate [21]. Importantly, the visible and infrared region absorption of $\mathrm{MoS}_{2}$ was greatly reduced due to the decorated transparent barium borate. Thus, the change in elemental composition along with morphology has created minor alterations in band structure which open up the possibility to explore different nonlinear absorption processes in the materials. The linear absorption coefficient of nanocomposites @ $800 \mathrm{~nm}$ (Fig. 4f) showed a nonlinear dependence at lower concentration of $\mathrm{MoS}_{2}$ which can be attributed to the dominance of $\mathrm{BBO}$ and change in morphology of composite. Here, BBO: (0.01 and $0.02 \mathrm{M}) \mathrm{MoS}_{2}$ composite possesses high linear transmittance in NIR region $(800 \mathrm{~nm})$ imitating the absorbance pattern of BBO, while BBO:0.03 $\mathrm{M} \mathrm{MoS}_{2} \mathrm{Com}$ posite shows high absorbance as like pure $\mathrm{MoS}_{2}$. It is also to be admitted that as hydrothermal method was adopted, control of $\mathrm{MoS}_{2}$ concentration was quiet challenging. Thus due to the inclusion of transparent BBO, the linear transmittance suffered a considerable change and among the samples, BBO: (0.01 $\mathrm{M} \mathrm{MoS}_{2}$ ) composite possess high linear transmittance in NIR region $(800 \mathrm{~nm})$ making them superior for optical limiting action in the NIR spectral region.

\section{Nonlinear optical studies: Z-Scan}

Z-Scan technique is an effective tool to understand the characteristic features of nonlinear interactions and measure third-order nonlinear optical properties such as nonlinear absorption (NLA) and nonlinear refraction (NLR) coefficients of the materials. Open-aperture and closed-aperture Z-scan patterns were recorded for both pure and BBO: $\mathrm{MoS}_{2}$ nanocomposites using femtosecond laser pulses (Ti: Sapphire, $800 \mathrm{~nm}, 150 \mathrm{fs}, 80 \mathrm{MHz}$ ) 
Fig. 4 Absorbance spectra of (a) pure MoS2 and barium borate decorated (b) 0.03 M MoS2 (c) $0.02 \mathrm{M} \mathrm{MoS2}$ (d) $0.01 \mathrm{M}$ MoS2 composites (e) pure barium borate [17] and (f) linear absorbance @800 nm
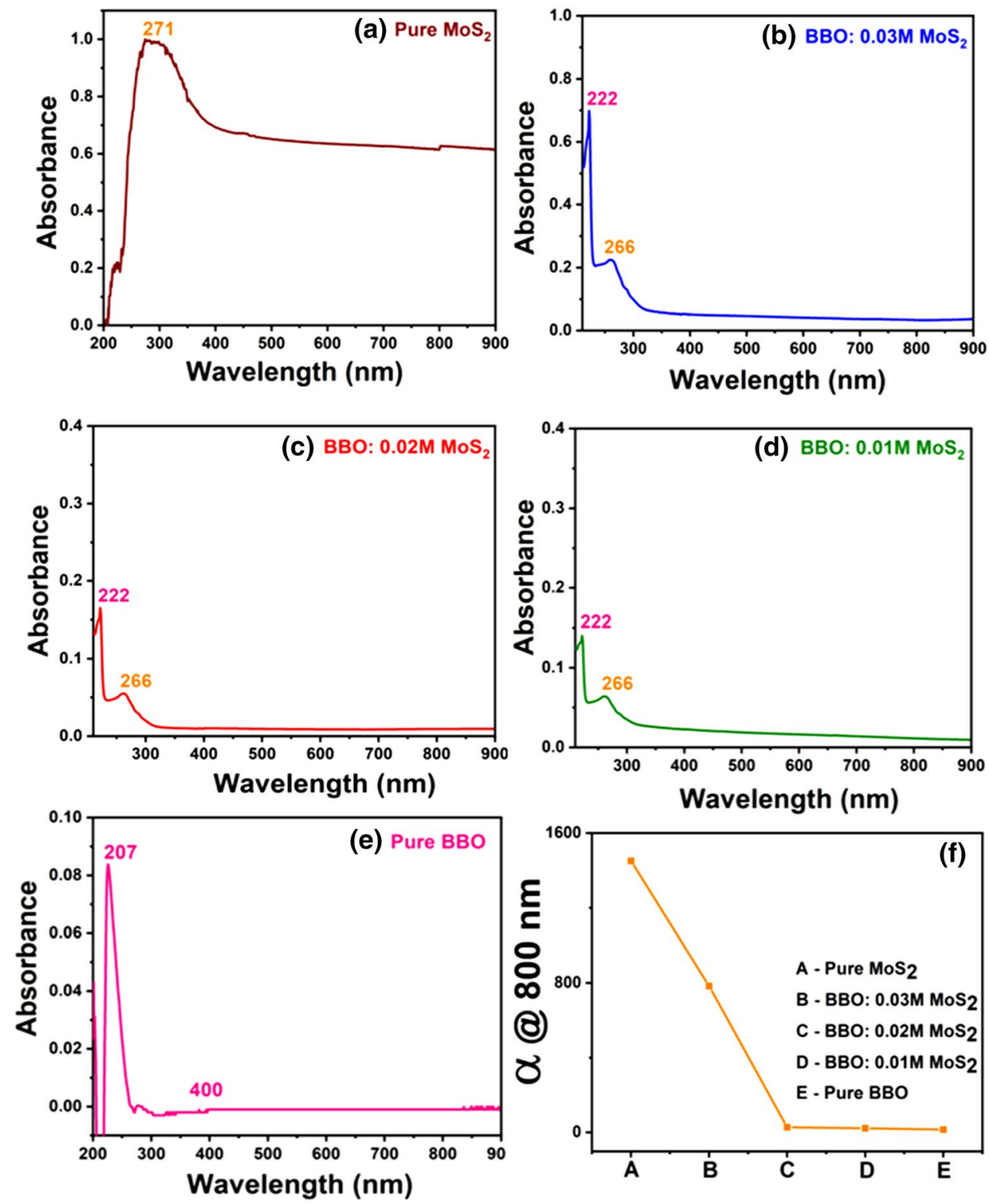

as an excitation source. Since the experiments were performed using high repetition rate pulses, thermal effects will also contribute to the observed NLO processes. In the typical experiment, the prepared samples were individually dispersed in ethylene glycol having $65 \%$ linear transmittance and were taken in a 1-mm-thick cuvette. The transmittance was measured as a function of sample position by moving the sample along the focussed beam. A graph was drawn between normalized transmittance $\left(T_{n}\right)$ and position $(Z)$ of the sample. A theoretical fit for the obtained experimental data was made using a nPA equation as proposed by Sheik-Bahae et al. [22]. The obtained open-aperture and closed-aperture patterns are shown in Figs. 5 and 7, respectively, in which solid lines represent the theoretical fits and the scattered data (circles) denote the experimental data. The following formulae from Sheik-Bahae formalism are used to estimate the normalized transmittance (nPA) of theoretically and are given by [23],

For an open aperture, $T_{n P A}=\frac{1}{\left[1+(n-1) \beta_{n} L\left(\frac{10}{1+\left(\frac{z}{z_{0}}\right)^{2}}\right)^{n-1}\right]^{\frac{1}{n-1}}}$ 

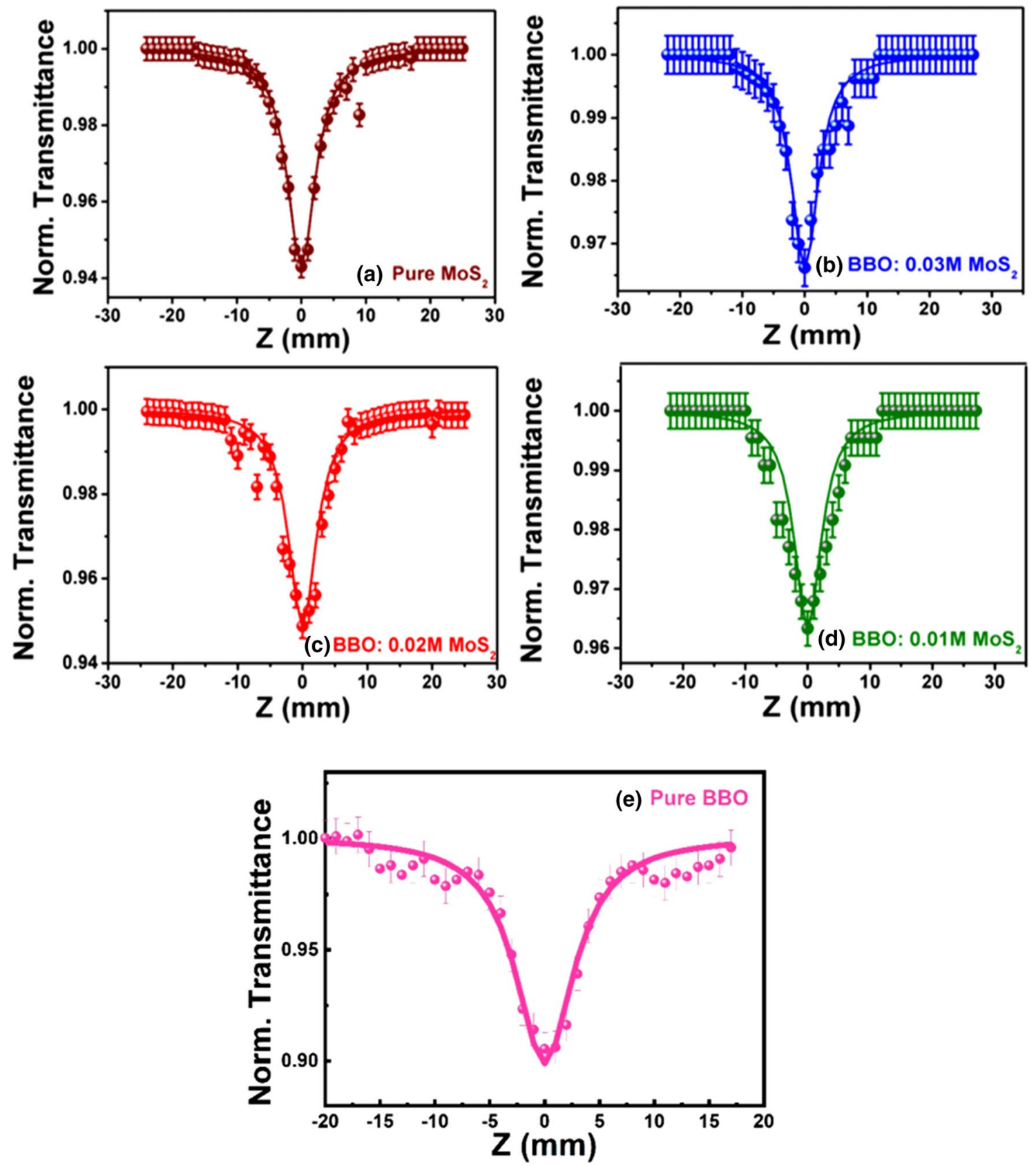

Fig. 5 Open-aperture Z-scan data of (a) pure $\mathrm{MoS}_{2}$ and barium borate decorated (b) $0.03 \mathrm{M} \mathrm{MoS}_{2}$ (c) $0.02 \mathrm{M} \mathrm{MoS}_{2}$ (d) $0.01 \mathrm{M} \mathrm{MoS}_{2}$ composites, (e) pure barium borate [17]. The excitation was with

For the closed aperture, $T_{C A}=1 \pm \frac{4 \Delta \emptyset\left(\frac{z}{z_{0}}\right)}{\left[1+\left(\frac{z}{z_{0}}\right)^{2}\right]\left[9+\left(\frac{z}{z_{0}}\right)^{2}\right]}$ where $\beta_{n}$ is the nonlinear absorption coefficient with $n$ as order of the nonlinear absorption $(n=1,2,3 \ldots),$,$L is$ the effective thickness of the sample, $I_{0}$ is the incident intensity of the laser beam at the focal point, $\left(z_{0}=\frac{\pi \omega_{0}^{2}}{\lambda}\right)$ femtosecond pulses ( $800 \mathrm{~nm}, 150 \mathrm{fs}, 80 \mathrm{MHz}$ ) with a peak intensity of $295 \mathrm{MW} / \mathrm{cm}^{2}$. Symbols are experimental data points, and the solid lines are theoretical fits to the data

is the Rayleigh length, and $\Delta \emptyset$ is the phase distortion of the transmitted laser beam due to refraction.

Open-aperture Z-scan technique was used to evaluate the nonlinear absorption of the material. Narrow and sharp valley pattern observed for pure and BBO decorated $\mathrm{MoS}_{2}$ demonstrates the occurrence of reverse saturable absorption (RSA) (Fig. 5), where the transmittance of light decreased with increase in light intensity. Theoretical fits made on the experimental data 
revealed the observed reverse saturable absorption can be ascribed due to two-photon absorption (2PA) and three-photon absorption (3PA) processes. It is interesting to observe that the experimental data of both pure $\mathrm{MoS}_{2}$ and BBO: $\mathrm{MoS}_{2}$ composite show best fit for both 2PA and 3PA equations. In the UV-Visible pattern, pure $\mathrm{MoS}_{2}$ possesses absorption in visible and NIR region and thus avails electronic states for 1 PA $(800 \mathrm{~nm}, 1.55 \mathrm{eV})$ and $3 P A(271 \mathrm{~nm}, 4.58 \mathrm{eV})$ processes directly. The literature shows the indirect bandgap value of $\mathrm{MoS}_{2}$ changes with the number of layers, and band structure calculated between $\mathrm{K}$ and $\Gamma$ points in the Brillouin zone can be used to display the possible transitions responsible for nonlinear absorption [1]. Strong absorption in the wavelength of excitation $(800 \mathrm{~m})$ suggests that the observed $3 P A$ is most likely to be a sequential (1PA + ESA induced genuine $2 \mathrm{PA}$ ) process rather than simultaneous (genuine $3 \mathrm{PA}$ ) process. The possible electronic transition involved in observed sequential 3PA of $\mathrm{MoS}_{2}$ (Fig. 6a) is as follows: under IR excitation, an electron absorbs a photon from the ground state $\left(E_{0}\right)$ and excite themselves to first excited state $\left(E_{1}, 1.55 \mathrm{eV}\right.$-inter band transition of $\mathrm{MoS}_{2}$ between ground state and $1 s_{A}$ state). Then, it simultaneously absorbs two photons to transit themselves to the third excited state $\left(E_{3}, 4.57 \mathrm{eV}\right.$-quasi continuum state of $\mathrm{MoS}_{2}$ ) leading to the possible sequential 3PA through $1 \mathrm{PA}+$ genuine $2 \mathrm{PA}$ process.

However, in the BBO: $\mathrm{MoS}_{2}$ (Fig. 6b) composite due to the dominance of $\mathrm{BBO}$, the material shows negligible absorption in NIR region. Earlier reports show that nonlinear absorption in pure BBO nanostructures excited with similar laser pulses exhibited 2PA process [17]. Unlike pure $\mathrm{MoS}_{2}$, due to the non-availability of near-resonant state of excitation, $\mathrm{BBO} \mathrm{MoS}_{2}$ composite undergoes genuine
3PA process (via virtual states and because sufficient peak intensity is available in the femtosecond pulses used). Here, the possible electronic transition responsible for genuine 3PA is as follows: an electron in ground state $\left(\mathrm{E}_{0}\right)$ absorbs three photons simultaneously to transit themselves to available first excited state $\left(E_{3}, 4.66 \mathrm{eV}\right.$ - quasi continuum state of $\mathrm{MoS}_{2}$ ) through genuine 3PA. In pure barium borate excited under similar laser (ultrashort pulse) excitation, the electrons in the lowest state could possibly be excited to the self-trapped exciton state by simultaneously absorbing two photons leading to genuine 2PA (Fig. 6c) [17]. Therefore, alteration in band structure resulted in sequential 3PA in $\mathrm{MoS}_{2}$ and genuine 3PA in BBO: $\mathrm{MoS}_{2}$. It is be mentioned here that to resolve and confirm the postulates of proposed mechanism, intensity-dependent Z-scan studies and transient absorption spectroscopic studies with femtosecond pulses are absolutely necessary. The estimated 2PA and 3PA absorption coefficients ( $\beta_{2 \mathrm{PA}}$ and $\left.\gamma_{3 \mathrm{PA}}\right)$ of both pure and BBO: $\mathrm{MoS}_{2}$ composite from the theoretical fits are summarized in Table 1. Considering the possible factors that can affect the experimental data like focal spot size, peak intensities, fitting procedures and calibration of intensity, the error value was fixed as $~ 5 \%$ for the chosen experimental condition. Similar error values are reported elsewhere in the literature and as the error correction is employed uniformly and the change in nonlinearity was directly compared. The error bars indicated in Figs. 5, 7 and 8 are indicative of possible inaccuracies in the data collection. We anticipate the maximum error resulting from such factors in the evaluated values of NLO coefficients to be $5 \%$. Similar reports on Z-scan measurement with error values are already available in the literature. It is interesting to observe that BBO: $\mathrm{MoS}_{2}$ composite possesses higher 3PA and 2PA coefficients than pure $\mathrm{MoS}_{2}$.
Fig. 6 Energy-level diagram demonstrating sequential 3PA for (a) Pure $\mathrm{MOS}_{2,}$ (b) genuine 2PA-induced ESA for BBO: $\mathrm{MoS}_{2}$ nanocomposite and (c) genuine 2PA for BBO [17]. Solid lines represent the available energy states and possible electron transitions during laser excitation. And virtual states are represented in dotted lines

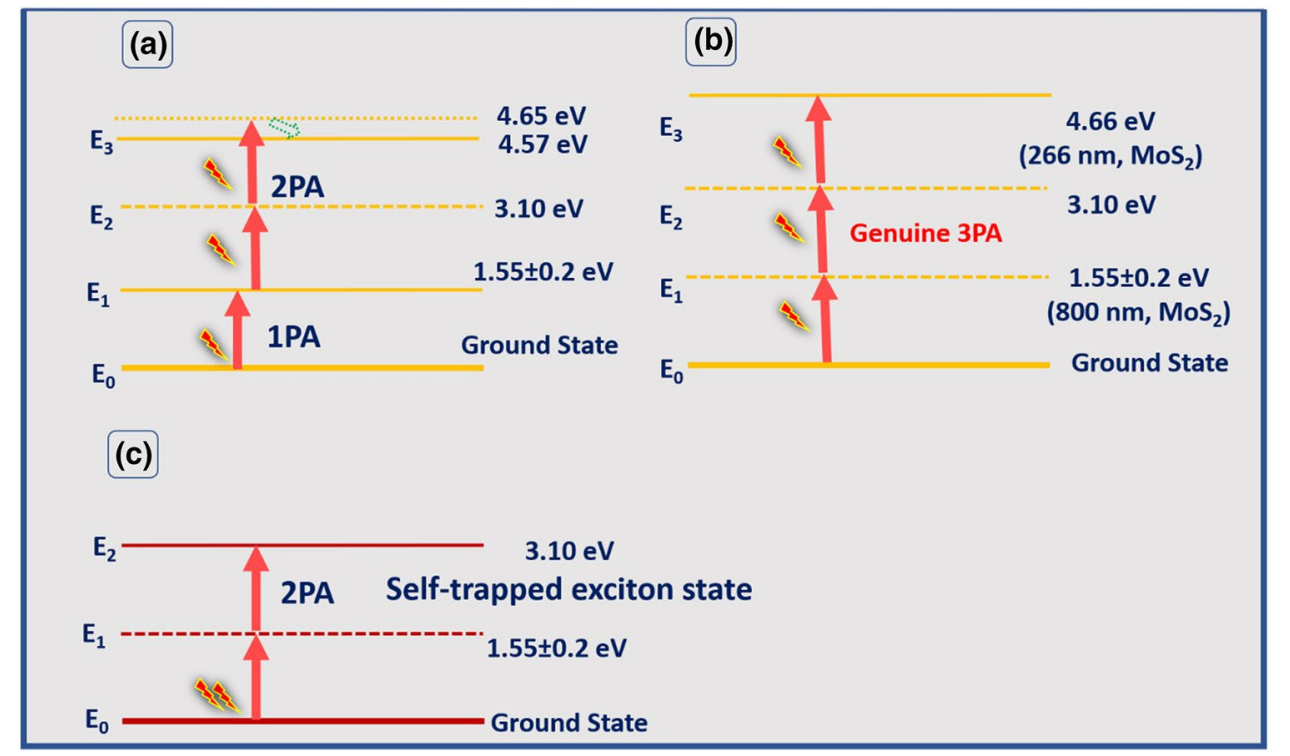

SN Applied Sciences A SPRINGER NATURE journa 
Table 1 2PA \& 3PA-induced NLO coefficients of Pure and BBO: $\mathrm{MoS}_{2}$ composites

\begin{tabular}{|c|c|c|c|c|c|}
\hline \multirow[t]{2}{*}{ S. no. } & \multirow[t]{2}{*}{ Sample name } & \multicolumn{4}{|c|}{ Femtosecond laser $(800 \mathrm{~nm}, 150 \mathrm{fs}, 80 \mathrm{MHz})$} \\
\hline & & $\begin{array}{l}\text { Nonlinear absorption } \\
\text { coefficient }\end{array}$ & $\begin{array}{l}\text { Nonlinear refractive } \\
\text { index }\left(\mathrm{n}_{2}\right) \\
\times 10^{-17} \mathrm{~m}^{2} / \mathrm{W}\end{array}$ & $\begin{array}{l}\text { NLO susceptibility } \\
\left(\chi^{(3)}\right) \\
\times 10^{-19} \mathrm{~m}^{2} / \mathrm{V}^{2}\end{array}$ & $\begin{array}{l}\text { Onset optical } \\
\text { limiting thresh- } \\
\text { old } \\
\mu \mathrm{J} / \mathrm{cm}^{2}\end{array}$ \\
\hline 1 & $\mathrm{MoS}_{2}$ & $\begin{array}{l}0.15 \pm 0.01 \times 10^{-21} \mathrm{~m}^{3} / \mathrm{W}^{2}(3 \mathrm{PA}) \\
5.45 \pm 0.27 \times 10^{-10} \mathrm{~m} / \mathrm{W}(2 \mathrm{PA})\end{array}$ & $2.28 \pm 0.11$ & $2.84 \pm 0.14$ & $0.16 \pm 0.1$ \\
\hline 2 & $\mathrm{BBO}: 0.03 \mathrm{M} \mathrm{MoS}_{2}$ & $\begin{array}{l}0.49 \pm 0.02 \times 10^{-21} \mathrm{~m}^{3} / \mathrm{W}^{2}(3 \mathrm{PA}) \\
5.26 \pm 0.26 \times 10^{-10} \mathrm{~m} / \mathrm{W}(2 \mathrm{PA})\end{array}$ & $-8.29 \pm 0.41$ & $9.91 \pm 0.49$ & $0.25 \pm 0.1$ \\
\hline 3 & BBO:0.02 $\mathrm{M} \mathrm{MoS}_{2}$ & $\begin{array}{l}2.12 \pm 0.11 \times 10^{-21} \mathrm{~m}^{3} / \mathrm{W}^{2}(3 \mathrm{PA}) \\
5.73 \pm 0.28 \times 10^{-10} \mathrm{~m} / \mathrm{W}(2 \mathrm{PA})\end{array}$ & $-11.1 \pm 0.55$ & $14.0 \pm 0.7$ & $0.11 \pm 0.1$ \\
\hline 4 & BBO:0.01 $\mathrm{M} \mathrm{MoS}_{2}$ & $\begin{array}{l}0.10 \pm 0.01 \times 10^{-21} \mathrm{~m}^{3} / \mathrm{W}^{2}(3 \mathrm{PA}) \\
5.01 \pm 0.25 \times 10^{-10} \mathrm{~m} / \mathrm{W}(2 \mathrm{PA})\end{array}$ & $-2.05 \pm 0.10$ & $3.09 \pm 0.15$ & $0.48 \pm 0.2$ \\
\hline 5 & $\mathrm{BBO}[17]$ & $6.50 \pm 0.32 \times 10^{-10} \mathrm{~m} / \mathrm{W}(2 \mathrm{PA})$ & $-1.00 \pm 0.05$ & $0.98 \pm 0.05$ & $0.39 \pm 0.2$ \\
\hline
\end{tabular}

However, 2PA coefficient of pure $\mathrm{BBO}$ is higher than bare $\mathrm{MoS}_{2}$ and BBO: $\mathrm{MoS}_{2}$ composite. In the composite, BBO: (0.02 M) $\mathrm{MoS}_{2}$ composite possesses higher value due to various factors like urchin morphology with microsphere structure of $\mathrm{MoS}_{2}$, 1D structure of barium borate and overlapping the transition states of barium borate and $\mathrm{MoS}_{2}$.

Nonlinear refractive index $\left(n_{2}\right)$ of the material was obtained from the closed-aperture Z-scan method. Pure $\mathrm{MoS}_{2}$ shows the valley followed by a peak pattern (Fig. 7a) indicating self-focusing behaviour with positive nonlinear refractive index. Self-focusing behaviour switches to the self-defocusing (peak followed by a valley as shown in Figs. 7b-d) nature as the sign is reversal and is associated with negative nonlinear refractive index due to the inclusion of barium borate in BBO: $\mathrm{MoS}_{2}$ composite. It is fascinating to note that the sign of nonlinear refractive index switches from negative to positive. Earlier reports show that pure barium borate nanoparticles exhibit negative nonlinear refraction [17]. In this experiment, thermo-optic effect cannot be completely neglected because high repetition rate of $80 \mathrm{MHz}$ was used in excitation source, and thus, the observed nonlinear refraction can be explained through thermal lens model. Under $800 \mathrm{~nm}, 150 \mathrm{fs}, 80 \mathrm{MHz}$ laser excitation, $\mathrm{MoS}_{2}$ showed self-focusing effect (positive nonlinear refraction leading to converging of laser), while BBO exhibited self-defocusing effect (negative nonlinear refraction leading to diverging of laser). Thus, the observed self-defocusing effect in BBO: $\mathrm{MoS}_{2}$ composite clearly exposed the dominance of $\mathrm{BBO}$ in the complex system. A change in refractive index as function of temperature induced during laser excitation creates two different lenses in $\mathrm{MoS}_{2}$ (Convex lens like) and BBO (Concave lens like). Therefore, due to dominance of $B B O$ in BBO: $\mathrm{MoS}_{2}$ composite, a change in the sign of nonlinear refractive index was observed. The estimated nonlinear refractive index $\left(n_{2}\right)$ of pure and barium borate decorated $\mathrm{MoS}_{2}$ is given in Table 1. Nonlinear refractive index of BBO: $\mathrm{MoS}_{2}$ was higher than the pure $\mathrm{MoS}_{2}$ and BBO. The superiority of $\mathrm{MoS}_{2}$ in nonlinear refraction arises predominantly from high thermal conductivity capability of $\mathrm{MoS}_{2}\left(2.3 \mathrm{Wm}^{-1} \mathrm{~K}^{-1}\right.$ for few layer $\mathrm{MoS}_{2}$ ) [24] with which it can transform the induced local heating during excitation (high repetition rate) resulting in stronger thermal lens model. Also, third-order nonlinear optical susceptibility of the all pure and compositing materials was estimated to be $2.84 \times 10^{-19} \mathrm{~m}^{2} / \mathrm{V}^{2}, 9.91 \times 10^{-19} \mathrm{~m}^{2} /$ $V^{2}, 14.0 \times 10^{-19} \mathrm{~m}^{2} / V^{2}$ and $3.08 \times 10^{-19} \mathrm{~m}^{2} / V^{2}$ for pure $\mathrm{MoS}_{2}$, BBO: $0.03 \mathrm{M} \mathrm{MoS2}$ BBO: $0.02 \mathrm{M} \mathrm{MoS}_{2}, \mathrm{BBO}: 0.01 \mathrm{M}$ $\mathrm{MoS}_{2}$, respectively. Among all the samples, BBO decorated on $0.02 \mathrm{M}$ concentration of $\mathrm{MoS}_{2}$ possesses a higher NLO coefficient such as nonlinear absorption $\left(\gamma_{3 P A}=2.12 \times 10^{-21} \mathrm{~m}^{3} / \mathrm{W}^{2}, \beta_{2 P A}=5.73 \times 10^{-10} \mathrm{~m} / \mathrm{W}\right)$, nonlinear refractive index $\left(n_{2}=-11.1 \times 10^{-17} \mathrm{~m}^{2} / \mathrm{W}\right)$ and third-order NLO susceptibility $\left(\chi^{(3)}=14 \times 10^{-19} \mathrm{~m}^{2} / \mathrm{V}^{2}\right.$ due to urchin morphology with the availability of spherical $\mathrm{MoS}_{2}$ (higher thermal stability against high repetition rate femtosecond laser) and 1D BBO rod (confined optical excitations).

Optical limiting curves were extracted from the open-aperture Z-scan data and using a fluence equation $\left(4 \sqrt{\ln 2} E_{\text {in }} / \pi^{3 / 2} \omega(z)^{2}\right)$ are shown in Fig. 8. The graphs represent a nonlinear pattern in which output transmittance changes nonlinearly with input fluence. And the deviation point at which the nonlinearity begins is termed as onset optical limiting behaviour of the material. Thus, the prepared materials can act as optical limiters that are transmitting a low intensity while blocking the high input intensity. Here, the observed optical limiting arises mainly due to nonlinear absorption (2PA and $3 \mathrm{PA}$ ) and nonlinear refraction (self-defocusing). 

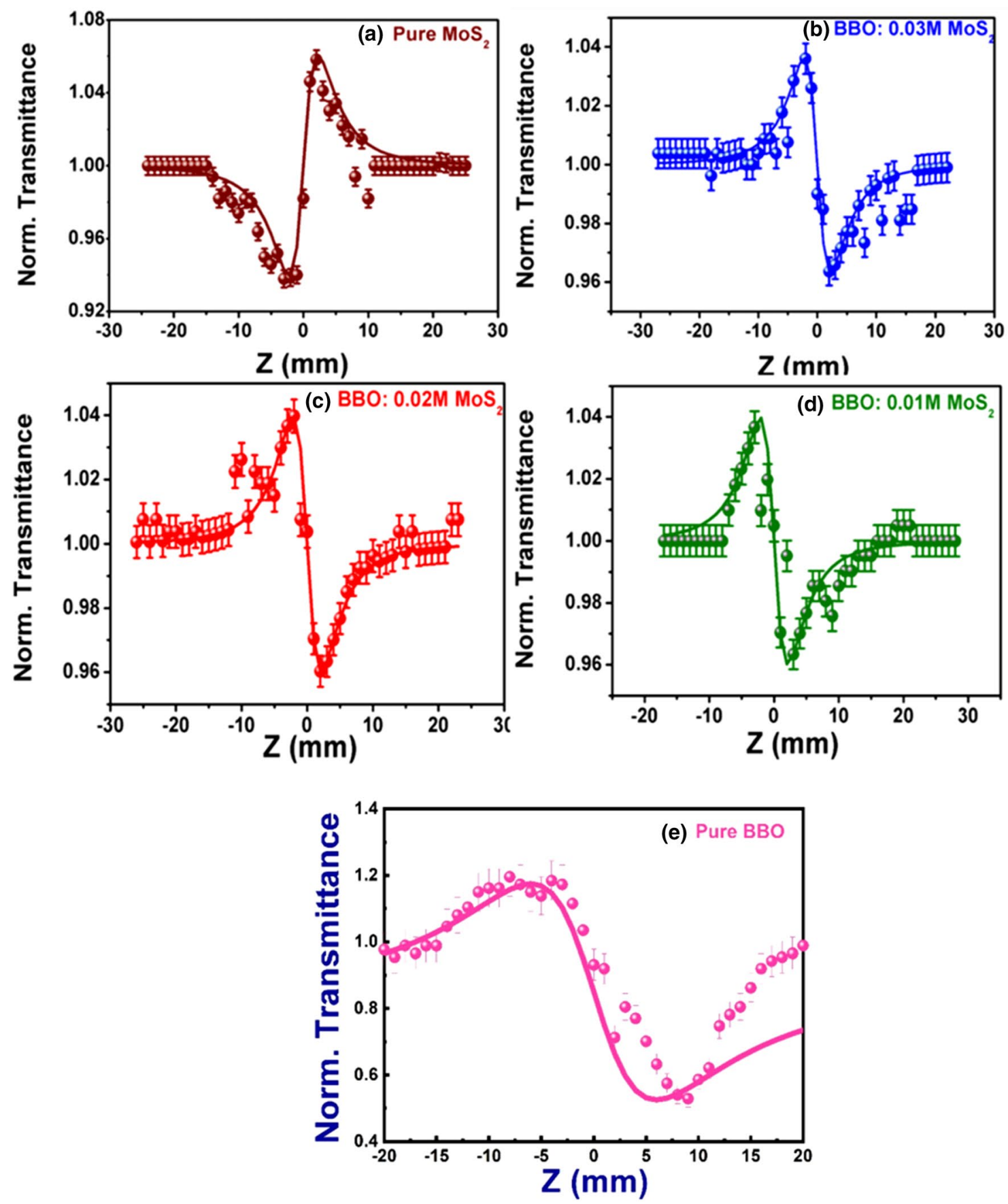

Fig. 7 Closed-aperture pattern of (a) pure $\mathrm{MoS}_{2}$ and barium borate decorated (b) $0.03 \mathrm{M} \mathrm{MoS}_{2}$ (c) $0.02 \mathrm{M} \mathrm{MoS}_{2}$ (d) $0.01 \mathrm{M} \mathrm{MoS}_{2}$ composites (e) pure barium borate [17]. The excitation was with fem- tosecond pulses ( $800 \mathrm{~nm}, 150 \mathrm{fs}, 80 \mathrm{MHz}$ ) with a peak intensity of $295 \mathrm{MW} / \mathrm{cm}^{2}$. Symbols are experimental data points, and the solid lines are theoretical fits to the data
Among the samples, onset optical limiting threshold of BBO decorate on $0.02 \mathrm{M}_{\text {of }} \mathrm{MoS}_{2}\left(0.11 \mu \mathrm{J} / \mathrm{cm}^{2}\right)$ and pure $\operatorname{MoS}_{2}\left(0.16 \mu \mathrm{J} / \mathrm{cm}^{2}\right)$ is lower than other composites. Further, these values are found to be lower than the reported values of other materials like copper niobite $\left(0.21 \mu \mathrm{J} / \mathrm{cm}^{2}\right)$ [23], bismuth $\left(2.16 \mu \mathrm{J} / \mathrm{cm}^{2}\right)$ [25] and zinc oxide $\left(128 \mu \mathrm{J} / \mathrm{cm}^{2}\right)$ [26] excited with similar laser. As optical limiting threshold is an important parameter in OL device fabrication, an extrapolation of OA data was done and the input fluence at which normalized 

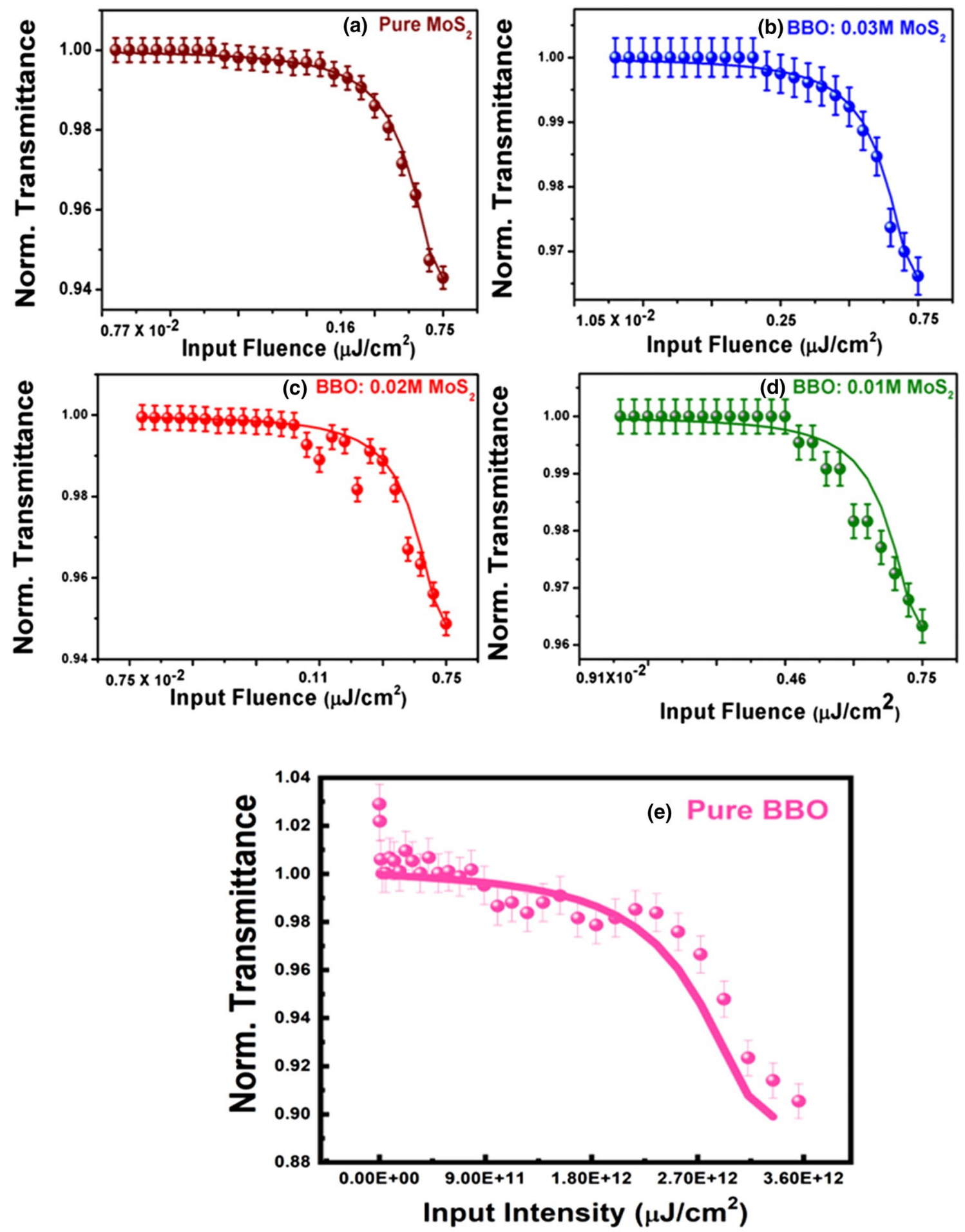

Fig. 8 Optical limiting curves of (a) pure $\mathrm{MoS}_{2}$ and barium borate decorated (b) $0.03 \mathrm{M} \mathrm{MoS}_{2}$ (c) $0.02 \mathrm{M} \mathrm{MoS}_{2}$ (d) $0.01 \mathrm{M} \mathrm{MoS}_{2}$ composites (e) pure barium borate [17]. The excitation was with fem-

transmittance becomes $50 \%$ was estimated to be few tens of $\mathrm{m} \mathrm{J} / \mathrm{cm}^{2}$ for all samples. A comparison of NLO coefficients of various composites excited with similar laser is presented in Table 2. Synergetic effects of tosecond pulses ( $800 \mathrm{~nm}, 150 \mathrm{fs}, 80 \mathrm{MHz}$ ) with a peak intensity of $295 \mathrm{MW} / \mathrm{cm}^{2}$. Symbols are experimental data points, and the solid lines are theoretical fits to the data

2PA/3PA- and self-defocusing-induced optical limiting with lower onset optical limiting threshold and higher NLO coefficients make BBO: $\mathrm{MoS}_{2}$ nanocomposite 
Table 2 Summary of the NLO coefficients of various composites excited with Ti: Sapphire laser pulses (at $800 \mathrm{~nm})$

\begin{tabular}{llll}
\hline Sample name & $\begin{array}{l}\text { Nonlinear absorption coef- } \\
\text { ficient }(\boldsymbol{\beta})\end{array}$ & $\begin{array}{l}\text { Nonlinear refractive index } \\
\left(\boldsymbol{n}_{2}\right)\end{array}$ & $\begin{array}{l}\text { Onset optical } \\
\text { limiting thresh- } \\
\text { old }\end{array}$ \\
\hline $\mathrm{MoS}_{2}-\mathrm{TiO}_{2}$ [12] & $1.77 \times 10^{-10} \mathrm{~m} / \mathrm{W}$ & - & $22.3 \mathrm{~mJ} / \mathrm{cm}^{2}$ \\
$\mathrm{MoS}_{2}-\mathrm{PMMA}[13]$ & $1.77 \times 10^{-10} \mathrm{~m} / \mathrm{W}$ & - & $21.5 \mu \mathrm{J} / \mathrm{cm}^{2}$ \\
$\mathrm{Fe}-\mathrm{Ag}[27]$ & $5.40 \times 10^{-15} \mathrm{~m} / \mathrm{W}$ & - & - \\
$\mathrm{Ag}-\mathrm{Polymer}[28]$ & $18 \times 10^{-12} \mathrm{~m} / \mathrm{W}$ & $2.8 \times 10^{-11} \mathrm{~cm}^{2} / \mathrm{W}$ & $38 \mathrm{~mJ} / \mathrm{cm}^{2}$ \\
$\mathrm{CdFe}_{2} \mathrm{O}_{4}-\mathrm{rGO}[29]$ & $21 \times 10^{-12} \mathrm{~m} / \mathrm{W}$ & $4.3 \times 10^{-16} \mathrm{~m}^{2} / \mathrm{W}$ & $0.65 \mu \mathrm{J} / \mathrm{cm}^{2}$ \\
\hline
\end{tabular}

preferable choice for laser safety devices for ultrashort IR laser pulses.

\section{Conclusions}

In summary, $\mathrm{MoS}_{2}$ microspheres and barium borate nanorods decorated $\mathrm{MoS}_{2}$ microspheres with urchinlike structure were prepared by hydrothermal method. Both $\mathrm{MoS}_{2}$ and BBO: $\mathrm{MoS}_{2}$ exhibited reverse saturable absorption due to 2PA and 3PA. Sequential and genuine 3PA processes occurred for pure $\mathrm{MoS}_{2}$ and barium borate decorated $\mathrm{MoS}_{2}$, respectively, and was confirmed with the aid of available energy states from absorption spectrum. Nonlinear refraction of pure $\mathrm{MoS}_{2}$ depicted self-focusing behaviour which switched to self-defocusing in BBO: $\mathrm{MoS}_{2}$ composite. The dynamic processes involved in the observed nonlinearity of $\mathrm{MoS}_{2}, \mathrm{BBO}$ and BBO: $\mathrm{MoS}_{2}$ composites are identified as sequential 3PA [ $\mathrm{E}_{0} \stackrel{1 P A}{\longrightarrow} \mathrm{E}_{1}$ (interband transition, $1.55 \mathrm{eV}$ ) $\stackrel{\text { genuine } 2 P A}{\longrightarrow} \mathrm{E}_{3}$ (continuum state, $4.58 \mathrm{eV})]$, genuine $2 \mathrm{PA}\left[\mathrm{E}_{0} \mathrm{E}_{0} \stackrel{\text { genuine2PA }}{\longrightarrow} \mathrm{E}_{2} \mathrm{E}_{2}\right.$ (self-trapped exciton state of $\mathrm{BBO}, 3.10 \mathrm{eV}$ )] and genuine $3 P A\left[E_{0} \stackrel{\text { genuine3PA }}{\longrightarrow} E_{3} E_{3}\right.$ (continuum state of $M_{0 S}, 4.66 \mathrm{eV}$ )], respectively. The tunability of NLO properties achieved by varying the content of $\mathrm{MoS}_{2}$ and BBO: (0.02 M) MoS nanocomposite possess high nonlinear absorption coefficient $(\beta)$, nonlinear refractive index $\left(\mathrm{n}_{2}\right)$ and third-order NLO susceptibility $\left(\chi^{(3)}=14.0 \times 10^{-19} \mathrm{~m}^{2} / \mathrm{V}^{2}\right)$. Multiphoton (nPA, $n=2,3$ )-induced optical limiting action in femtosecond IR domain was demonstrated both for pure $\mathrm{MoS}_{2}$ and BBO: $\mathrm{MoS}_{2}$ composite and lower onset optical limiting threshold of $\sim \mu \mathrm{J} / \mathrm{cm}^{2}$ opens the possibility of utilizing BBO:(0.02 M) MoS for laser safety devices and as an energy stabilizer in microjoule lasers based surgery.

\section{Compliance with ethical standards}

Conflicts of interest There are no conflicts to declare.

\section{References}

1. Khudyakov DV, Borodkin AA, Lobach AS, Mazin DD, Vartapetov SK (2019) Optical nonlinear absorption of a few-layer $\mathrm{MoS}_{2}$ under green femtosecond excitation. Appl Phys B 125:73

2. Ma C, Wang C, Gao B, Adams J, Wu G, Zhang H (2019) Recent progress in ultrafast lasers based on $2 \mathrm{D}$ materials as a saturable absorber. Appl Phys Rev 6:041304

3. He J, Tao L, Zhang H, Zhou B, Li J (2019) Emerging 2D materials beyond graphene for ultrafast pulse generation in fiber lasers. Nanoscale 11:2577-2593

4. Kumar NA, Dar MA, Gul R, Baek JB (2015) Graphene and molybdenum disulfide hybrids: synthesis and applications. Mater Today 18:286-298

5. Cao J, Zhou J, Zhang Y, Liu X (2017) A clean and facile synthesis strategy of $\mathrm{MoS}_{2}$ nanosheets grown on multi-wall CNTs for enhanced hydrogen evolution reaction performance. Sci Rep 7:8825

6. Wen X, Gong Z, Li D (2019) Nonlinear optics of two dimensional transition metal dichalcogenides. Info Mat 1:317-337

7. Edvinsson $T$ (2018) Optical quantum confinement and photocatalytic properties in two-, one-and zero-dimensional nanostructures. R Soc Open Sci 5:180387

8. Lezama IG, Arora A, Ubaldini A, Barreteau C, Giannini E, Potemski M, Morpurgo AF (2015) Indirect-to-direct band gap crossover in few-layer MoTe ${ }_{2}$. Nano Lett 15:2336-2342

9. He M, Quan C, He C, Huang Y, Zhu L, Yao Z, Xu X (2017) Enhanced nonlinear saturable absorption of $\mathrm{MoS}_{2} /$ graphene nanocomposite films. J Phys Chem C 121:27147-27153

10. Wei R, Zhan H, Hu Z, Qiao T, He X, Guo Q, Qiu J (2016) Ultrabroadband nonlinear saturable absorption of high-yield $\mathrm{MoS}_{2}$ nanosheets. Nanotechnology 27:305203

11. Qu B, Ouyang Q, Yu X, Luo W, Qi L, Chen Y (2015) Nonlinear absorption, nonlinear scattering, and optical limiting properties of $\mathrm{MoS}_{2}-\mathrm{ZnO}$ composite-based organic glasses. Phys Chem Chem Phys 17:6036-6043

12. Wei R, Tian X, Hu Z, Zhang H, Qiao T, He X, Qiu J (2016) Vertically standing layered $\mathrm{MoS}_{2}$ nanosheets on $\mathrm{TiO}_{2}$ nanofibers for enhanced nonlinear optical property. Opt Express 24:25337-25344

13. Liang G, Tao L, Tsang YH, Zeng L, Liu X, Li J, Wen Q (2019) Optical limiting properties of a few-layer $\mathrm{MoS}_{2} / \mathrm{PMMA}$ composite under excitation of ultrafast laser pulses. J Mater Chem C 7:495-502

14. Babeela $C$, Girisun TS, Vinitha G (2015) Optical limiting behavior of $\beta-\mathrm{BaB}_{2} \mathrm{O}_{4}$ nanoparticles in pulsed and continuous wave regime. J Phys D Appl Phys 48:065102

15. Zhang Y, Lu D, Yu H, Zhang H (2019) Low-Dimensional Saturable Absorbers in the Visible Spectral Region. Adv Opt Mater 7:1800886 
16. Feng G, Wei A, Zhao Y, Liu J (2015) Synthesis of flower-like $\mathrm{MoS}_{2}$ nanosheets microspheres by hydrothermal method. J Mater SciMater Electron 26:8160-8166

17. Girisun TCS, Somayaji RM, Priyadarshani N, Rao SV (2017) Femtosecond third order optical nonlinearity and optical limiting studies of ( $\gamma$ and $\beta$ )—barium borate nanostructures. Mater Res Bull 87:102-108

18. Lin Hongtao, Xiaoya C, Hongling L, Min Y, Yanxing Q (2010) Hydrothermal synthesis and characterization of MoS2 nanorods. Mater Lett 64:1748-1750

19. Li X, Zhu H (2015) Two-dimensional MoS2: properties, preparation, and applications. J Materiomics 1:33-44

20. Lee Jung E, Jaemin J, Taeg YK, Sujin K, Seong-IK Junghyo N, Sunmin R, Ki TN, Min HL (2017) Catalytic synergy effect of MoS 2/ reduced graphene oxide hybrids for a highly efficient hydrogen evolution reaction. RSC Adv 7:5480-5487

21. Muruganandi G, Saravanan M, Vinitha G, Raj MJ, Girisun TS (2018) Barium borate nanorod decorated reduced graphene oxide for optical power limiting applications. Opt Mater 75:612-618

22. Sheik-Bahae M, Said AA, Van Stryland EW (1989) High-sensitivity, single-beam $n_{2}$ measurements. Opt Lett 14:955-957

23. Priyadarshani N, Rao SV, Girisun TS (2016) Investigation of the femtosecond optical limiting properties of monoclinic copper niobate. Appl Phys B 122:256
24. Gandi AN, Schwingenschlögl U (2016) Thermal conductivity of bulk and monolayer $\mathrm{MoS}_{2}$. EPL 113:36002

25. Yang C, Shang ZJ, Wang Z, Peng H, Tang XD, Li B, Chen Y (2015) Size control of semimetal bismuth nanoparticles and the UV - visible and IR absorption spectra. Int J Opt 44:7-11

26. Shaik UP, Kumar PA, Krishna MG, Rao SV (2014) Morphological manipulation of the nonlinear optical response of $\mathrm{ZnO}$ thin films grown by thermal evaporation. Mater Res Express 1:046201

27. Sridharan K, Endo T, Cho SG, Kim J, Park TJ, Philip R (2013) Single step synthesis and optical limiting properties of $\mathrm{Ni}-\mathrm{Ag}$ and Fe-Ag bimetallic nanoparticles. Opt Mater 35:860-867

28. Misra N, Rapolu M, Rao SV, Varshney L, Kumar V (2016) Nonlinear optical studies of inorganic nanoparticles-polymer nanocomposite coatings fabricated by electron beam curing. Opt Laser Technol 79:24-31

29. Saravanan M, Girisun TCS, Rao SV (2017) Super-paramagnetic and unusual nonlinear absorption switching behaviour of an in situ decorated $\mathrm{CdFe}_{2} \mathrm{O}_{4}-\mathrm{rGO}$ nanocomposite. J Mater Chem C 5:9929-9942

Publisher's Note Springer Nature remains neutral with regard to jurisdictional claims in published maps and institutional affiliations. 